\title{
Literature Review on Imitation Innovation Strategy
}

\section{Mingyue Hu}

School of Business Administration, South China University of Technology, Guangzhou, China

Email: humingyueee@163.com

How to cite this paper: Hu, M.Y. (2018) Literature Review on Imitation Innovation Strategy. American Journal of Industrial and Business Management, 8, 1777-1788. https://doi.org/10.4236/ajibm.2018.88120

Received: July 16, 2018

Accepted: August 17, 2018

Published: August 20, 2018

Copyright $\odot 2018$ by author and Scientific Research Publishing Inc. This work is licensed under the Creative Commons Attribution International License (CC BY 4.0).

http://creativecommons.org/licenses/by/4.0/

\section{c) (i) Open Access}

\begin{abstract}
The progress of science and technology and the development of innovation activities are the important impetus for the rapid development of China's economy. Due to the low level of technology, insufficient funds and scarce resources of scientific and technological innovation, China's innovation strategy tends to imitate technological innovation. For developing countries, this model of imitation and innovation has indeed played an important role in improving a country's technological conditions and laid a technological foundation for catching up with developed countries. First, this paper defines the concept of imitation innovation, analyzes the relationship between the imitation innovation and independent innovation, the issue between imitation innovation and intellectual property, the influence factors of imitation innovation; secondly, the influence of imitation innovation on enterprise innovation performance is summarized. Finally, the future research of imitation innovation is prospected.
\end{abstract}

\section{Keywords}

Imitation Innovation, Independent Innovation, Intellectual Property, Enterprise Performance

\section{Introduction}

With the development of economic globalization and the Internet, the earth is connected as a whole, and the speed and ability of knowledge generation and transmission have changed. It has created opportunities and conditions for countries to learn and imitate advanced technologies of other countries, and enterprises in developing countries can get late-development advantages by imitating and innovating on the basis of predecessors. Imitation innovation strategy in the 1990's gradually had an important effect on the development of China's 
enterprises, such as Tencent, its first product OICQ was an imitation of the United States launched ICQ, but Tencent wasn't completely copy, it selected the imitation innovation strategy, got rid of the stale and brought forth the fresh innovation, formed its own characteristics. The copycat innovation strategy explains why Tencent has grown so far, while the first American company to launch ICQ has long since disappeared.

In recent years, many scholars have focused on the imitation innovation strategy, aware of its importance, studied the imitation innovation strategy, but because the definition of various scholars for the imitation innovation is different, the view about on the present stage of China which innovation strategy should be taken is different, the study of imitation innovation and enterprise performance is rare, so it is necessary to conclude the idea about imitation innovation strategy research to form a holistic view.

This paper through defining the concept of imitation innovation, analyzes the relationship between the imitation innovation and independent innovation, the problem between imitation innovation and intellectual property, and the influence factors of imitation innovation, then it can help enterprise get a comprehensive view about the most appropriate innovation strategy of the enterprise. By summarizing the influence of imitation innovation on enterprise innovation performance, this paper provides some theoretical basis for enterprises to choose innovation strategy for improving enterprise performance and realizing long-term development. On the basis of summarizing the previous literatures, this paper puts forward the future prospect of the research on imitation innovation strategy and promotes the development of China's imitation innovation strategy research.

\section{Literature Review}

\subsection{The Definition of Imitation Innovation}

Since 1978, the technological innovation ability of Chinese enterprises has been improved, the performance of technological innovation improved significantly, and has emerged a large number of outstanding enterprises who have technical innovation ability, good economic benefit and competitive advantages in the domestic and international market. There are two main sources of innovation technology: internal research and development or independent innovation. Technology is derived from the enterprises' internal technical breakthrough, emphasize on its own strength, through independent research and development activities, its essence is firmly grasp the initiative and ownership of the core link of innovation. Second, external introduction, that is, technology introduction. If developing countries through their own independent research and development for the technology, the costs will much higher than the introduction of other ready-made similar technology [1]. Technological innovation divides innovation modes into three types: independent innovation, imitation innovation and cooperative innovation [2]. The meaning of independent innovation is to complete 
the whole process of technological innovation mainly by relying on the strength of the enterprise itself. Cooperative innovation refers to the joint efforts of different enterprises and actors for a certain technological innovation.

Many scholars have defined the meaning of imitation innovation, imitation innovation is defined as: the enterprise which is enticed by multiple factors, especially the fact that pioneering innovators is profitable, then they through learning, imitation, take the pioneering experience, methods of innovators and lesson, in the later period of innovation chain invest a lot of talented personnel, financial and material resources, get the competitive advantage of the respect such as quality, price and cost, gradually taking the leading innovator in the market, obtain certain economic benefits of innovation [3]. Someone argue that imitation innovation refers to the innovators learn innovative thinking, experience and behavior, to buy or to decipher the core technology and the technical secret, to improve the technology [4]. This behavior is on the basis of the market characteristics and trends, then further the development of innovation. The other one believed that imitation innovation is essentially an innovation behavior [2]. "Imitation" is a further effort on the basis of others, also known as secondary innovation.

The concept of imitation innovation has been misunderstood as plagiarism, stealing other people's work and being lazy and unwilling to think for a long time. According the comprehensive definition of imitation innovation, we can find that the core of the imitation innovation is to produce new things, on the basis of predecessors' technology combined with its own actual situation and needs, to develop this enterprise's new products. Rather than completely copy, its essence is a kind of innovation behavior.

In recent years, the documents of the relevant domestic imitation innovation mainly focus on the problem between imitation innovation and intellectual property, the relationship between imitation innovation and independent innovation and the relationship between imitation innovation and enterprise performance. This paper summarizes the contents of these aspects in order to summarize the current situation of China's imitation innovation research and put forward the future prospect of the imitation innovation research.

\subsection{Research on Imitation Innovation and Intellectual Property Rights}

As to whether copycat innovation can obtain intellectual property rights, some scholars have proposed that copycat innovation may also generate independent intellectual property rights [5]. The most typical is Japan, which, in fact, has improved its technological level to become a world economic power through imitation and innovation. China's tencent, for example, has built its empire through imitation innovation.

Some scholars consider the protection of intellectual property rights on the relationship between the independent innovation and imitation abroad late-development countries, analyzed the late-development countries with lead- 
ing technology gap and imitation ability influence on the protection of intellectual property rights system arrangement, think the intellectual property rights to restrict imitation innovation [6]. Emulation of legitimate with the rationality of the existence, free imitation (or free competition) to protect business achievement (or creative achievements) is need to be properly balanced, the basic principle that deal with the relationship between them is that allowed by imitating competitors' products or services to compete, but not against a fair and infringes on the creative achievements of the protected [7], on the other hand, if reasonable use of intellectual property rights literature has the promoting effect on the imitation innovation, through the patent document retrieval, understanding of relevant technical information, tracking competitors, reduce development costs, avoid technology trade dispute [8], and provide the basis for a comprehensive evaluation on the imported technology, such as using the patent literature information resources, can play a role of its multiple, to enterprise's technological innovation is very important and even the survival and development.

China's patent law divides patents into three categories: invention patents, utility model patents and design. Invention patent, with high levels of innovation is the product, method or the improvement of the proposed new technical solution, often in terms of technical principle is new, most invention patent, also known as the "original". The utility model is a practical new technical scheme for the shape, structure or combination of products, and a new combination of existing technical elements. Appearance design is the product's shape, pattern, color, or its combination of rich aesthetic feeling and is suitable for industrial application of the new design, from the perspective of technology innovation is thought to be creative with the lowest, product technology did not change. After two patents would not require be substantial changes in the technical aspects, but they can also form the intellectual property rights, and the two patents in the market competition is also very meaningful, many products in the market competition is mainly in the two level [2].

It is generally believed that improper imitation of original innovation results will infringe others' intellectual property rights. Of existing intellectual property system in China as the way to mimic made relevant provisions: first, the technology import, the right holder has obtained assignment or licensing of intellectual property rights object of imitation. Second, through the reverse engineering way of imitation, such as starting from foreign products, product decomposition analysis and comprehensive research. Thirdly, imitation through "improving patent". Fourth, we should imitate intellectual products that are not protected by intellectual property law. Fifth, the use of intellectual property time and regional imitation. Sixth, the use of a loophole in the patent claims and the description of text to imitate, the above are just imitate, does not constitute infringement, for in the proper category imitation innovation and get results is should be protected by intellectual property rights to explain [9].

The current situation of Chinese enterprises is that innovation is " $90 \%$ imita- 
tion, $10 \%$ breakthrough". Most enterprises follow the technical route of "reverse" decomposition and imitation innovation. Enterprises generally ignore long-term, platform and frontier technology research and development, and continue to rely on imported technology and imported parts. On this basis, such innovation is mainly derivative technology innovation on the basis of the introduction platform. Only a few enterprise groups can construct technical barriers and make breakthroughs in platform technology and frontier technology. The result of derivative innovation is patents based on utility models and designs, while the proportion of invention patents that constitute the most technical barriers is extremely low. Current our country much-needed research in intellectual property protection should be how to protect domestic enterprises' legal imitation innovation at the same time stimulate the enterprise independent innovation enthusiasm and technical barriers, improve its efficiency.

\subsection{Research on the Relationship between Imitation Innovation and Independent Innovation}

Guo believed that countries have a better understanding of their own actual development situation and needs, and the technology formed by independent innovation will be more closely linked to the actual needs of their own production [10]. Therefore, the introduction of frontier technology is not the optimal strategy for the development of technology. Moreover, a country has completed a technological innovation can make use of its kind with no technological innovation of the technology gap between other countries for technical products in the international trade, this is because the technical advantage, to ensure that its monopoly in some products, you can get a lot of profit.

Independent innovation is the highest level of technological innovation in enterprises. In the long run, independent innovation is the strategic choice that enterprises ultimately pursue. Since the independent innovation strategy is aimed at technological lead and market lead, such a strategy will show obvious advantages in competition [11]. First of all, independent innovation helps enterprises to build strong technical barriers for themselves. Secondly, the enterprise of independent innovation sets the goal of technology independent breakthrough and leading development as its pursuit, and seeks for a breakthrough in a brand-new technology field, with a large space for innovation. Thirdly, independent innovation is beneficial for enterprises to cultivate their $\mathrm{r} \& \mathrm{~d}$ capability and improve the overall level of technology accumulation. Independent innovation while higher learning cost than the imitation innovation, can develop products with independent intellectual property rights, avoid most of the market profits as foreign output feedback technology. Enterprises can achieve leapfrog development by implementing independent innovation and forming core competitiveness through continuous technological progress. Imitate innovator is a follower of advanced technology, which determines the passive adaptability, in the process of technology development is difficult to formulate technology accumulated long-term planning, difficult to consolidate and develop independent 
marketing channel, can only follow the change of the market. However, independent innovation requires the first place in the region to have strong economic strength, high investment in research and development, and strong ability to bear the high risk of independent innovation. Second, it has strong scientific and technological strength, advanced research and development institutions and high-level scientific and technological talents. Third, there is a sensitive information feedback system and decision-making system, and a public service organization that can fully mobilize the enthusiasm of all aspects of technological innovation. Developing countries are struggling to meet these demands.

Engel and Kleine believe that enterprises can create their own innovation through imitation [12]. Besides $r$ \& $d$ innovation, imitation of excellent products, processes and management systems is also an important source of innovation [13]. Posen proposed that only when the useful knowledge and ability of the imitator were combined with the knowledge obtained from the leader company, the company would have the opportunity to successfully surpass the leader [14]. The unity of imitation and innovation is imitation and innovation. As an innovative way, imitation innovation can also create sustainable competitive advantages for enterprises, especially for backward enterprises in developing countries. The difference between the imitation innovation and independent innovation is the different way of innovation, independent innovation model in terms of its original intention is to show the enterprise through their own efforts and exploration technology breakthrough, especially for the core technology breakthrough on its own [2]. Although we now place great emphasis on independent innovation, in view of the technological level of Chinese enterprises, the choice of technological innovation model should be based on technological imitation and innovation. Compared with independent innovation, imitation innovation has greater advantages. From a technical level, the imitation innovation is the first innovators in the absorption on the basis of successful experience and failure lessons, fosters strengths and circumvents weaknesses, effectively avoids risk in research and development, reduces development costs, improves the research and development success rate [9]. From the perspective of the level of production, the imitation innovation enterprises unable to receive priority advantages in product development section, then focus on product manufacturing link, its products in quality, performance, prices are more competitive, higher economic benefits; From the perspective of the market, enterprises have stronger market foresight, which can avoid the loss caused by the silent period of the product market and reduce the cost of product publicity. When the emulation of enterprise's cost is less than the benefits, the enterprise market through constantly learning, trial and error, and will gradually adjust their innovation strategy, tend to imitation innovation, innovation market will form a dual structure, part of the enterprise will give priority to with the independent innovation, another part of the enterprise will be given priority to with imitation innovation [15]. The benign interaction between the two can achieve the optimal allocation of innovative resources and avoid the waste of resources caused by excessive innovation in 
the whole society.

From the perspective of international experience, any give full play to the advantage of backwardness "technology to catch up with countries and regions, true to independent innovation to give priority to, is the overall technical level has reached the world advanced level, have very strong economic power. Of the most successful Japanese, until 1994 officially proposed "farewell to imitate and improved" era, but in the early 1980s Japan enterprise technical level has reached the advanced world level in most areas [16], products have strong competitiveness in the international market, to the late 1980s and early 90's, some areas of technology is in the world leading level, has no "imitation" model, national strategy was shifted from "technical state" to "science and technology to create Chinese".

Neither domestic scholars' research on China nor foreign scholars' research on developing countries can distinguish imitation innovation from independent innovation. The foreign literature basically limits the innovation of developing countries to imitation innovation, which undoubtedly denies the existence of independent innovation of developing countries. In developed countries, imitation innovation also exists, and the innovation strategy cannot be determined according to the development degree of a country. And for the same country, innovation strategies in different regions are not necessarily the same. Due to the height of the modern technology integration, making each item of the so-called independent innovation more or less there are always some imitation of ingredients in the same way, in the reality of technological innovation, there is no complete imitation. For every imitation innovation enterprise, as long as the enterprises in the process of imitation composition contains its own innovation, then no matter how big is the imitation of ingredients, which must have the enterprises "own composition". For an enterprise to grow in the process of the grasp of the relationship between independent innovation and imitation innovation, important is to grasp the enterprise growing accumulation and innovation strength changes, how to arrange the proportion of independent development in technology innovation and imitation.

For developing countries, scholars need to study when to choose to imitate innovation strategy and when to change to independent innovation strategy. China's research in this area still needs to be rich.

\subsection{Research on Factors Influencing Imitation Ability}

The influence factors of imitation innovation ability can come from enterprise internal and external analysis: on the one hand, the enterprise's own ability, strong absorption ability, technical ability, innovation ability and marketing ability, will affect the enterprise imitation innovation ability; On the other hand, external factors such as industry characteristics, economic environment and government factors are also important.

The ability of enterprises to imitate and innovate was mainly related to their 
rapid reaction ability, learning and absorption ability, technological improvement ability, mass production ability and marketing ability [17]. These abilities determine how much knowledge an enterprise can acquire at what speed [18]. Kozhikode believes that enterprises without necessary absorption capacity can only adopt blind imitation [19]. Only enterprises with absorptive capacity can choose to innovate themselves and implement creative imitation.

In developing countries, governments play an important role in setting development goals, providing direction and providing support. Kim on the analysis of the Korean electronics industry, pointed out that the government's policy to the south Korean companies are of great success, in the process of establishing the south Korean electronics industry, the government plays a crucial role, and the government's support to help South Korea electronics company focus on product design, production capacity and imitation innovation [19]. In addition, the corporate culture will also influence the success of imitation innovation. Although imitation innovation is also carried out, the influence of different industry characteristics on imitation innovation is very different. The cultural environment of enterprises will also influence the implementation of imitation innovation, and the innovative cultural environment is more conducive to strengthening the innovation behavior of organizations. From the aspect of organizational culture, Robert showed that organizational innovation culture has a significant positive impact on its innovation productivity [20]. When Enrique Claver studied the influence of organizational culture on enterprise innovation ability, he pointed out that organizational innovation culture is the basis of organizational innovation behavior and innovation performance [21]. Innovation-oriented culture is an organic combination of organizational innovation values, organizational structure, innovative behaviors and innovative thinking, with the purpose of encouraging and inspiring innovative ideas of employees [22]. As a special way of innovation, imitation innovation also has an important influence on the cultural types of enterprises.

Existing literature mainly from the Angle of enterprise's own ability and the government, to analyze the influence of various factors on the imitation innovation, but not to analyze the influence of the size of the weight, when not all factors to the enterprise to improve its competitive advantage, independent innovation and imitation innovation enterprises how to choose? For example, when its own ability is more suitable for imitation innovation, but national policies strongly support independent innovation and set restrictions on imitation innovation, how should enterprises choose?.

\subsection{Research on the Relationship between Imitation Innovation and Enterprise Performance}

Imitation innovation as a way of innovation, focus on imitating creative adaptation, on the basis of technological leapfrogging, purpose is through to adapt to the new environment, meet customer demand, thus improve enterprise innovation performance, beyond the competitors. The simple imitation, however, only 
hopes to survive in the huge competitive market. With the development of leading enterprises, it has no significant impact on the improvement of corporate performance.

Many researches on imitation innovation focus on its definition, pattern, type and influencing factors. There are few studies on the influence of incomplete imitation innovation on enterprise performance. The early research on the influence of imitation innovation on enterprise performance mainly comes from case study, and there are few empirical articles. Although the literature is not much, but the existing literature has shown that under the condition of environmental uncertainty, fuzzy, imitators in imitation of leader core advantage, on the basis of improvement, innovation, helps to mimic beyond leader, gain a competitive advantage [23], at the same time, the imitation innovation as one of the innovation mode [24], is the source of enterprise innovation.

The influence of imitation innovation on enterprise innovation performance can also be analyzed from the aspects of capacity building, technology improvement and brand value. From the aspects of capacity building, Kim in the auto industry, for example, through the investigation to the following technology development and innovation, found enterprise mainly as a initial imitators, imitate the technology of developed countries, replicate, improvement, and then built step by step, improve their innovation ability. Not only that, Japan's successful industrial development also benefited from the imitation innovation strategy, by absorbing the advanced technology, the introduction of product innovation to develop themselves in the face of market competition ability [25]. Some scholars combined with China's actual situation, proposed the imitation innovation in the emerging world development paths-from the initial copy stage, to mold a stage, to the original phase [26]. Kale and Little based on the ability to create model, research the learning process of Indian pharmaceutical industry and the rapid accumulation of technology [27], found that Indian pharmaceutical industry along the path repeated imitation to innovation, accelerate the technical expertise of chasing, and technical ability from imitation to advanced enterprise development laid a solid foundation for the innovation of the research and development ability, to enhance the pharmaceutical research and development of the value chain. From the perspective of technology improvement, Lee analyzed the improvement of technology capability of Taiwan's electronic industry and attributed the improvement of enterprise technology to the imitation and innovation [28]. Ethiraj think, imitators one of methods to obtain competitive advantage is trying to develop the level of the enterprise product differentiation into vertical differentiation technology, that is, from focus on product diversity and attribute differences into focus on quality and performance differentiation, through the study of the vertical differentiation of product, is advantageous to the enterprise leader, occupy the market share, improve enterprise performance [29]. In terms of brand value, Huang took fast retailing group as an example to analyze how uniqlo develops its value and brand image, and proposed the im- 
portance of imitation innovation [30]. Fast retailing group continuously explore and accept from other enterprise management concept and combining with its own situation, to develop its business model by means of trial and error and create new customer value, thus promoting the improvement of the brand value. And Posen in the research of the relationship between imitation and enterprise heterogeneity, points out that imitation is different from completely copy, it can through recombination mechanisms, on the basis of imitating target matching and mix their own practice, produce heterogeneity, thus improve enterprise performance.

Imitation innovation and business performance of Chinese enterprises this aspect of the study is less, most of existing research are focus on the whole, such as the accumulation of tangible and intangible resources, improve the management efficiency and reduce management costs, and to find opportunities to profit level, and about the performance directly linked with the enterprise operating income, operating profit seldom involved in these aspects, this aspect of the theory to be extended.

\section{Conclusions and Future Research}

Through sorting out the above aspects, the research on incomplete imitation innovation mainly focuses on the following aspects:

1) the conceptual connotation of imitation innovation; 2) the relationship between imitation innovation and independent innovation; 3) problems between imitation innovation and intellectual property rights and influencing factors of imitation innovation 4) influence of imitation innovation on enterprise innovation performance, but for imitation innovation is how to affect enterprise performance research of obvious deficiencies. Imitation is not only a powerful mechanism for enterprises to improve their operating performance, but also an important source for enterprises to acquire knowledge. In future studies, imitation innovation can focus on the following aspects:

a) Enriching the antecedent variables that influence imitation innovation. Although some scholars have pointed out the factors influencing imitation innovation, most of them are about corporate culture, industry characteristics and institutional environment. In addition, imitation innovation also relies on the acquisition and integration of internal and external innovation resources. Therefore, in the future, we can start from the source of innovation and explore which innovation resources can promote imitation innovation.

b) To deeply explore the relationship between imitation innovation and enterprise performance. Including the imitation innovation strategy, how to influence and how to improve enterprise performance through the imitation innovation strategy, in order to choose what kind of innovation strategy, and build provide theoretical basis for its innovation strategy system in the process of technology innovation and development for the enterprise.

c) Carry out empirical research in the Chinese context. At present, most of the 
researches on imitation innovation are mainly carried out through case analysis or simulation analysis, and there are few empirical researches. Therefore, in future research, we can carry out empirical research on this subject in the Chinese context.

\section{Conflicts of Interest}

The authors declare no conflicts of interest regarding the publication of this paper.

\section{References}

[1] Zhang, P.G. (2007) Course of Development Economics-Revised Edition. Economic Science Press, Beijing.

[2] Peng, J.S. and Liu, B.J. (2003) Imitation Innovation and Intellectual Property Protection. Scientific Research, 21, 423-427.

[3] Qian, C.H. (2001) Imitation Innovation-Choice of Western Enterprise Innovation Strategy. Soft Science, 15, 53-58.

[4] Wu, C.N. (2009) A Review of Domestic and Foreign Research on Imitation Innovation. Technology and Innovation Management, 30, 1-3.

[5] Chen, C.B. (2009) Intellectual Property Strategy. Science Press, Beijing.

[6] Yi, X.Z., Zhang, Y.B. and Liu, Z.Y. (2007) Independent Innovation, Foreign Imitation and Protection of Intellectual Property Rights in Developing Countries. World Economy, No. 3, 31-40.

[7] Zhu, Y.L. (2011) Imitation and Innovation in New Product Development. Enterprise Reform and Management, No. 4, 36-37.

[8] Zhu, L.L. (2008) Regulation of Intellectual Property Law Based on Imitation and Innovation. Huazhong University of Science and Technology, Wuhan.

[9] Li, N. (2011) Intellectual Property Rights of Chinese Enterprises to Imitate Innovation. Business Guide, No. 16, 175-176.

[10] Guo, W. (2009) From Independent Innovation to Imitation Innovation: The Choice that Conforms to China's Reality. Economic Problems, No. 12, 14-16.

[11] Huang, Y. (2006) Analysis and Suggestions on Advantages and Disadvantages of Independent Innovation and Imitation Innovation. China Science and Technology Information, No. 4, 30.

[12] Engel, C. and Kleine, M. (2015) Who Is Afraid of Pirates? An Experiment on the Deterrence of Innovation by Imitation. Research Policy, 44, 20-33. https://doi.org/10.1016/j.respol.2014.07.020

[13] Shenkar, O. (2010) Copycats: How Smart Companies Use Imitation to Gain a Strategic Edge. Strategic Direction, 26, 3-5. https://doi.org/10.1108/02580541011080474

[14] Posen, H.E. and Sangyoon, Y.I. (2013) The Power of Imperfect Imitation. Strategic Management Journal, 34, 149-164. https://doi.org/10.1002/smj.2007

[15] Lu, Y.M. (2008) Research on the Choice of Enterprise Independent Innovation and Imitation Innovation Model Based on Evolutionary Game. Science and Technology Management Research, No. 184, 25-27.

[16] Gu, G. and Zhang, X. (2003) Application of System Dynamics in Regional Innovation System Research. Science and Technology Management, 24, 10-13. 
[17] Fu, J. and Cheng, Y. (1998) Facing the Challenge of Knowledge Economy, What Should We Grasp?-On the Relationship between Technological Innovation and Knowledge Innovation.

[18] Sajeva, M., Augugliaro, C., Smith, M.J., et al. (2013) Regulating Internet Trade in CITES Species. Conservation Biology, 27, 429-430. https://doi.org/10.1111/cobi.12019

[19] Li, J. and Kozhikode, R.K. (2008) Knowledge Management and Innovation Strategy: The Challenge for Latecomers in Emerging Economies. Asia Pacific Journal of Management, 25, 429-450. https://doi.org/10.1007/s10490-007-9076-X

[20] Kim, Y., Kwon, S., Dongsik, Y., et al. (1997) A Novel, Bright Blue Electroluminescent Polymer: A Diphenylanthracene Derivative. Chemistry of Materials, 9, 2699-2701. https://doi.org/10.1021/cm970586x

[21] Johnson, R.W. (1993) An Introduction to the Bootstrap. Chapman \& Hall, London, 49-54.

[22] Xu, Q., Xie, Z. and Yang, Z. (2004) Comprehensive Innovation Management (TIM): A New Paradigm of Strategic Innovation Management. Research and Development Management, 16, 1-8.

[23] Claver, E., Llopis, J., Garcia, D., et al. (1998) Organizational Culture for Innovation and New Technological Behavior. Journal of High Technology Management Research, 9, 55-68. https://doi.org/10.1016/1047-8310(88)90005-3

[24] Yang, G., Li, B. and Xia, B. (2015) Neglected Innovation: Review and Prospect of Non-R\&D Innovation Research. Technological Progress and Countermeasures, No. $16,149-154$

[25] Chen, C.P. (2011) Dynamics and Architectures of Innovation Systems. Massachusetts Institute of Technology, Cambridge.

[26] Lu, X. and Sun, J. (2011) Core Competence and Imitation Innovation Path of Enterprises-Perspective of Emerging Countries. Economic Theory and Economic Management, 31, 64-71.

[27] Ethiraj, S.K., Levinthal, D. and Roy, R.R. (2008) The Dual Role of Modularity: Innovation and Imitation. INFORMS, 939-955.

[28] Kale, D. and Little, S. (2007) From Imitation to Innovation: The Evolution of R\&D Capabilities and Learning Processes in the Indian Pharmaceutical Industry. Technology Analysis \& Strategic Management, 19, 589-609. https://doi.org/10.1080/09537320701521317

[29] Lee, S.G. and Sang, M.L. (2009) An Analytical Study of Innovation and Imitation Effects on Technology Adoption Based on Venkatraman.

[30] Huang, P.Y., Kobayashi, S. and Isomura, K. (2014) How UNIQLO Evolves Its Value Proposition and Brand Image: Imitation, Trial and Error and Innovation. Strategic Direction, 30, 42-45. https://doi.org/10.1108/SD-04-2014-0058 